\title{
Acute Vertebral Fracture
}

Abby N. Agulnek, do ${ }^{1}$ Kevin J. O'Leary, mo ${ }^{1}$ Beatrice J. Edwards, $\mathrm{mD}^{2}$

\author{
${ }^{1}$ Division of Hospital Medicine, Feinberg School of Medicine, Northwestern University, Chicago, Illinois. \\ ${ }^{2}$ Bone Health and Osteoporosis Center, Division of Geriatric Medicine, Feinberg School of Medicine, \\ Northwestern University, Chicago, Illinois.
}

Disclosure: Nothing to report.

Vertebral fractures resulting from osteoporosis are a significant cause of morbidity and mortality in the aging population and are commonly seen in the hospital setting. Appropriately assessing and treating these conditions continues to be a challenge. This article is an evidence-based clinical update on the evaluation and management options of acute vertebral fractures, ranging from conservative treatment to surgical intervention. Hospitalists can play an influential role in the management of osteoporosis. Journal of Hospital Medicine 2009;4:E20-E24. @ 2009 Society of Hospital Medicine.

KEYWORDS: fracture, kyphoplasty, osteoporosis, osteoporosis fracture, spine fracture, vertebral compression fracture, vertebral fracture, vertebroplasty.

An 89-year-old female presents to the Emergency Department with lower back pain for the past 5 days. The patient has a past medical history of polymyalgia rheumatica and hypothyroidism. Her medications include prednisone $10 \mathrm{mg}$ daily and levothyroxine $50 \mu \mathrm{g}$ daily. Aside from tenderness over the third lumbar vertebra, her physical exam is unremarkable. An x-ray shows a fracture of the third lumbar vertebra. Basic laboratory studies, including calcium and creatinine are normal.

\section{The Clinical Problem and Impact}

Vertebral fractures (often termed vertebral compression fractures) affect approximately $25 \%$ of all postmenopausal women. ${ }^{1,2}$ Only one-third of vertebral fractures are brought to medical attention. ${ }^{3,4}$ In the remaining two-thirds, patients are either asymptomatic or do not seek medical attention. The lifetime risk of a clinical vertebral fracture is approximately $16 \%$ and $5 \%$ in white women and men, respectively. ${ }^{1}$ The risk of vertebral fracture increases with age, lower bone mineral density (BMD), and prior vertebral fracture. ${ }^{1,5}$ Women with a preexisting vertebral fracture have a 5-fold increased risk for a new vertebral fracture relative to those without a history of vertebral fracture. ${ }^{5,6}$ Approximately $20 \%$ of women who sustain a vertebral fracture will have a new vertebral fracture in the subsequent year. ${ }^{5,6}$ Vertebral fractures are frequently overlooked on chest x-rays and hence there is a need for increased awareness and improved recognition of radiographically-demonstrated fractures. ${ }^{7}$ Hospitalists must appreciate that a vertebral fracture is often the first clue to underlying osteoporosis. At least $90 \%$ of vertebral and hip fractures are attributable to osteoporosis. ${ }^{5}$

Typically, the pain related to an acute vertebral fracture improves over 4 to 6 weeks. ${ }^{8,9}$ However, pain can persist, resulting in functional impairment, and a decline in the quality of life. ${ }^{10-13}$ Vertebral fractures may lead to kyphosis and reduced lung function. This, in turn, may increase the risk for pneumonia, the most common cause of death in patients with osteoporosis. ${ }^{4}$ Both clinical and subclinical vertebral fractures are, in fact, independently associated with increased mortality, ${ }^{4,14,15}$ particularly in the period immediately following the event. ${ }^{16}$ The economic impact of osteoporosis and its related fractures is substantial. ${ }^{17-19}$ In 1995, the annual direct medical cost for the inpatient care of vertebral fractures was estimated to be $\$ 575$ million. ${ }^{19}$

\section{Evidence-Based Approach to the Hospitalized Patient Evaluation}

Vertebral fractures most commonly occur between $\mathrm{T} 7$ and L4. Acute vertebral fracture pain is typically sudden in onset and located in the mid to lower back. The pain may occur while performing an ordinary task such as lifting an object or bending over, although in many cases there is no preceding trauma. Physical activity exacerbates the pain and patients' movements may be limited due to pain. Spinal tenderness is usually present. A history of weight loss, prior malignancy, or fever should serve as red flags to the hospitalist and prompt evaluation for underlying malignancy or infection.

For a suspected fracture, frontal and lateral radiographs of the thoracolumbar spine are the initial imaging of choice. Magnetic resonance imaging (MRI) is useful when infection, malignancy, or spinal cord compression is suspected. The presence of neurological deficits should always prompt imaging with MRI or computed tomography (CT).

Patients with vertebral fractures should be evaluated with bone density testing, as osteoporosis is usually the underlying etiology. Because a number of medical conditions commonly contribute to bone loss (Table 1), laboratory testing is indicated for most patients. Although debate exists as to the optimal testing strategy, ${ }^{20}$ the National Osteoporosis Foundation guidelines recommend the evaluation of blood count, chemistry, and thyroid-stimulating hormone (TSH) 


\begin{tabular}{ll} 
TABLE 1. Secondary Causes & of Low Bone Mineral \\
Density & Hypogonadism \\
$\begin{array}{l}\text { Endocrine disease or } \\
\text { metabolic causes }\end{array}$ & Cushing's syndrome \\
& Hyperthyroidism \\
& Anorexia nervosa \\
& Hyperparathyroidism \\
Nutritional conditions & Vitamin D deficiency \\
& Calcium deficiency \\
& Malabsorption \\
Drugs & Glucocorticoids \\
& Antiepileptic drugs \\
& Excessive thyroid medication \\
& Long-term heparin or low molecular weight \\
& heparin therapy (eg, $>1$ month) \\
& Multiple myeloma \\
Other & Rheumatoid arthritis \\
& Organ transplantation \\
\hline
\end{tabular}

in patients with osteoporosis. ${ }^{21}$ Because vitamin $\mathrm{D}$ deficiency is common in patients who sustain osteoporotic fractures, 25-hydroxyvitamin D levels should be checked in most patients. ${ }^{22-25}$ Depending on the clinical scenario, additional testing may include the following: serum testosterone, serum intact parathyroid hormone (PTH), 24-hour calcium excretion, serum protein electrophoresis, urine protein electrophoresis, erythrocyte sedimentation rate, and celiac sprue antibodies. $^{26}$

\section{Management \\ Short Term}

Short-term management goals include the relief of pain and recovery of mobility. Nonsteroidal antiinflammatory drugs (NSAIDs) and low-dose opioid medications should be used first in an effort to relieve pain. Beyond its potential effect on bone density, calcitonin (Miacalcin, Fortical) has long been used in acute vertebral fractures for analgesia. A systematic review of 5 randomized controlled trials concluded that calcitonin significantly reduced the pain from acute vertebral fractures. ${ }^{27}$ Calcitonin improved pain as early as 1 week into treatment and the benefit was persistent at 4 weeks. The analgesic mechanism of action for calcitonin is not entirely clear. Proposed mechanisms include increased $\beta$-endorphin release, an antiinflammatory effect, and a direct effect on specific receptors in the central nervous system. . $^{27,28}$

Pamidronate (Aredia) also has shown efficacy at reducing acute fracture pain. In a double-blinded trial, Armigeat et al. $^{29}$ evaluated pamidronate $30 \mathrm{mg}$ daily for 3 days as compared to placebo in 32 patients. Pain scores were improved at 7 and 30 days with pamidronate. The mechanism of analgesia is unclear. Bisphosphonates are known to inhibit osteoclast activity, but may also work by blocking the effect of inflammatory cytokines. ${ }^{29}$
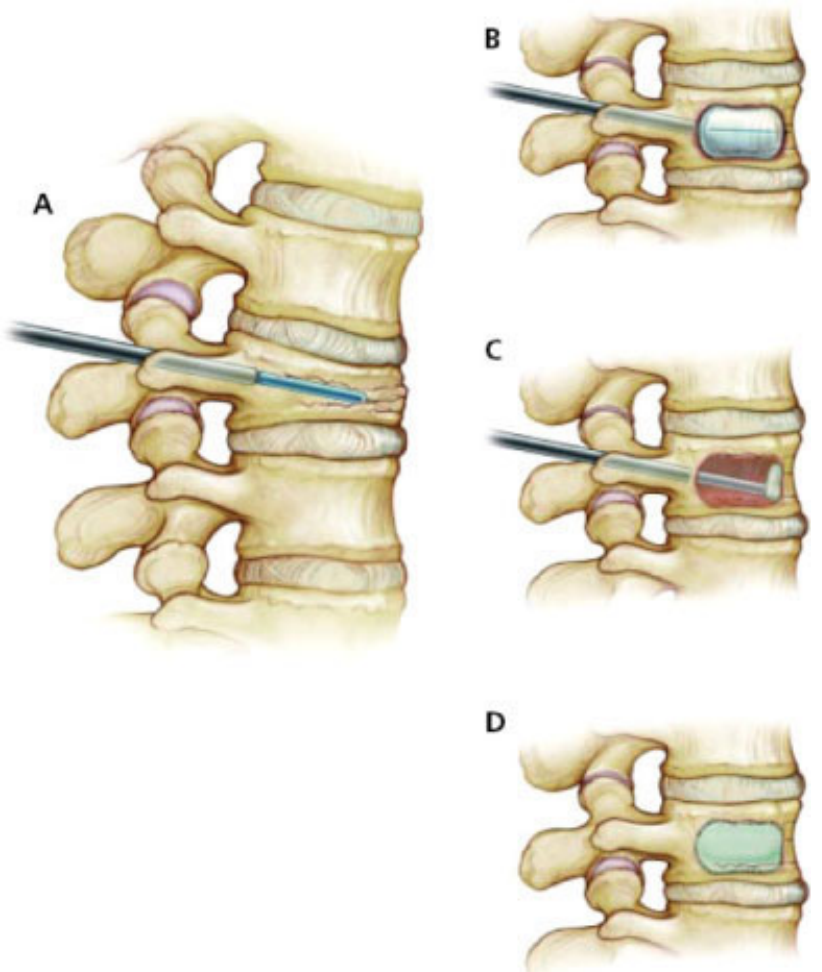

FIGURE 1. Kyphoplasty. (A) In kyphoplasty, a cannula is placed into the collapsed vertebra, through which an inflatable bone tamp is inserted into the vertebral body. (B) The bone tamp is inflated, and (C) the cavity is filled with polymethylmethacrylate cement. (D) The hardened cement forms an internal cast. [Adapted from Mazanec et al. ${ }^{36}$ with permission]

Early pain relief is critical in order to encourage physical activity. Bed rest should be avoided, as immobility may increase the risk for pressure ulcers, venous thromboembolism, and pneumonia. ${ }^{30-33}$ Although bracing is frequently used in acute vertebral fracture, the modality has not been formally studied. Although also not well studied in the acute setting, physical therapy has been shown to reduce pain and improve functioning for patients with chronic pain from vertebral fracture, ${ }^{34}$ and is generally recommended. ${ }^{35}$

Percutaneous vertebral augmentation procedures include vertebroplasty and kyphoplasty. In vertebroplasty, polymethylmethacrylate cement is injected through a needle under fluoroscopic guidance into the collapsed vertebral body. With kyphoplasty, balloon tamps are used to elevate vertebral endplates prior to injection of cement (Figure 1). ${ }^{36}$ The proposed mechanism of action for both procedures is stabilization of the fracture by the hardened polymethylmethacrylate cement. These procedures are commonly performed by interventional radiologists without the need for general anesthesia; however, depending on the institution, they may be done by orthopedic surgeons, neurosurgeons, or anesthesiologists. The procedure can be performed as an outpatient, if indicated. Although the volume of these procedures has grown dramatically in recent years, ${ }^{37,38}$ the quality of 
evidence supporting their use is relatively weak. ${ }^{39-41}$ Only 1 randomized controlled trial has been published evaluating the potential benefit of vertebroplasty over conservative management. ${ }^{42}$ Voormolen et al. ${ }^{42}$ evaluated patients with vertebral fractures and pain refractive to 6 weeks of optimal medical therapy. Patients were treated with vertebroplasty or continuation of medical therapy. Vertebroplasty significantly improved pain initially, but not after 2 weeks. Like the study by Voormolen et al., ${ }^{42}$ most studies evaluating percutaneous vertebral augmentation procedures have been conducted on patients with long-term pain refractory to medical management. One notable exception is a nonrandomized trial published by Diamond et al. ${ }^{6}$ In that study, 55 patients were treated with vertebroplasty while 24 were treated conservatively. Pain at 24 hours was significantly improved in patients treated with vertebroplasty. At 6 weeks, however, there was no difference among the 2 groups.

The risk of short-term complications from vertebral augmentation procedures is difficult to assess in light of the small sample sizes and methodological limitations of existing studies. Cement leakage occurs in $40 \%$ to $41 \%$ of patients treated with vertebroplasty, as compared with $8 \%$ to $9 \%$ with kyphoplasty. ${ }^{39,41}$ Pulmonary emboli occur in $0.6 \%$ and $0.01 \%$ of patients treated with vertebroplasty and kyphoplasty, respectively, while neurologic complications occur in $0.6 \%$ and $0.03 \%$ of patients. ${ }^{41}$ Concern exists about whether percutaneous vertebral augmentation procedures might increase the risk for subsequent fractures, ${ }^{43,44}$ as the incidence of new fractures appears to be elevated in the period immediately following the procedure and approximately two-thirds of new fractures occur in vertebrae adjacent to the augmented vertebra. ${ }^{39,41,44}$ However, the $20 \%$ incidence of new vertebral fractures in the year following vertebral augmentation is similar to the fracture rate seen in patients not treated with osteoporosis therapy. ${ }^{44}$

Assessment of the impact of vertebral augmentation procedures on the cost of care is limited by the lack of highquality clinical studies. ${ }^{45,46}$ Randomized controlled trials evaluating the benefit and risk of these procedures compared to conservative management are underway. ${ }^{4-49}$ Pending further evidence, these procedures are best reserved for patients who fail to benefit from other measures to control pain and improve mobility.

\section{Long Term}

A comprehensive discussion of the long-term management of osteoporosis is beyond the scope of this work. However, the inpatient setting presents an opportune time to initiate long-term medical therapy. Studies show that the majority of patients who sustain osteoporotic fractures do not receive pharmacologic treatment for osteoporosis. ${ }^{50-53}$ Hospitalists have the opportunity to start medications that can reduce the risk for subsequent fracture by nearly 50\%. ${ }^{54-58}$ A total calcium intake of 1200 to $1500 \mathrm{mg}$ per day and vitamin D of 400 to 800 IU per day are recommended for all postmeno- pausal women. Patients who smoke should receive smoking cessation counseling and be considered for pharmacologic treatment for tobacco dependence. All patients should be assessed for fall risk, including a review of medications and assessment of alcohol intake.

Before considering pharmacologic treatment for osteoporosis, secondary causes of low bone mass must be excluded. Bisphosphonates are generally considered first-line pharmacologic therapy for osteoporosis. Alendronate (Fosamax), risedronate (Actonel), and ibandronate (Boniva) have been shown in randomized trials to increase bone density and reduce the risk of osteoporotic fractures. ${ }^{55,56,59}$ Daily, weekly, and monthly preparations of bisphosphonates now exist. Pill-induced esophagitis is a potential adverse effect of bisphosphonate therapy, but is extremely rare if proper precautions are taken. Patients should take oral bisphosphonates on an empty stomach, with a full glass of water, sitting upright, and have nothing to eat or drink for at least one half hour. If compliance with oral bisphosphonates is not possible, or esophageal abnormalities preclude oral bisphosphonate use, one may consider the use of intravenous ibandronate or zoledronic acid (Reclast). A 3-year randomized controlled trial of yearly zoledronic acid improved bone density and reduced the incidence of osteoporotic fractures. ${ }^{60}$ Bisphosphonates are generally not recommended when creatinine clearance is less than $30 \mathrm{~mL} /$ minute. Other pharmacologic options for the treatment of osteoporosis include selective estrogen receptor modulators and anabolic agents. The reader is referred to an excellent review by $\operatorname{Rosen}^{61}$ for additional discussion of these therapies. The American College of Rheumatology clinical guidelines for the management of glucocorticoid induced osteoporosis are also worthy of review. ${ }^{62}$

Hospitalists are naturally suited to improve the quality of care for patients hospitalized with vertebral fractures. Most patients who currently sustain osteoporotic fractures do not receive appropriate evaluation and treatment. One study used an interdisciplinary team to identify, assess, and begin treatment for appropriate patients hospitalized with osteoporotic fractures. ${ }^{63}$ The intervention resulted in significantly more patients taking osteoporosis treatment medications 6 months after the incident fracture.

\section{Conclusions}

Acute vertebral fracture is a common clinical problem associated with significant morbidity and increased risk of mortality. Treatment of vertebral fracture should include analgesics and physical therapy. Percutaneous augmentation procedures may be considered in patients who fail optimal medical therapy. Because most vertebral fractures are due to osteoporosis and the healthcare system currently fails to appropriately assess and treat most patients who have sustained osteoporotic fractures, hospitalists are in an optimal position to initiate long-term preventative treatment for these patients. 


\section{Address for correspondence and reprint requests:}

Abby N. Agulnek, DO, Northwestern Memorial Hospital, Division of Hospital Medicine, 251 E. Huron Street, Feinberg 16-738, Chicago, IL 60611; Telephone: 312-926-5924; Fax: 312-926-6134; E-mail: agulnek@md.northwestern.edu Received 7 February 2008; revision received 18 October 2008; accepted 23 October 2008

\section{References}

1. Melton LJ, 3rd. Epidemiology of spinal osteoporosis. Spine. 1997;22(24 suppl):2S-11S

2. Melton LJ 3rd, Lane AW, Cooper C, Eastell R, O'Fallon WM, Riggs BL. Prevalence and incidence of vertebral deformities. Osteoporos Int. 1993; 3(3):113-119.

3. Cooper C, O'Neill T, Silman A. The epidemiology of vertebral fractures. European Vertebral Osteoporosis Study Group. Bone. 1993;14(suppl 1): S89-S97.

4. Kado DM, Browner WS, Palermo L, Nevitt MC, Genant HK, Cummings SR. Vertebral fractures and mortality in older women: a prospective study. Study of Osteoporotic Fractures Research Group. Arch Intern Med. 1999;159(11):1215-1220.

5. Ross PD, Davis JW, Epstein RS, Wasnich RD. Pre-existing fractures and bone mass predict vertebral fracture incidence in women. Ann Intern Med. 1991;114(11):919-923.

6. Lindsay R, Silverman SL, Cooper C, et al. Risk of new vertebral fracture in the year following a fracture. JAMA. 2001;285(3):320-323.

7. Gehlbach SH, Bigelow C, Heimisdottir M, May S, Walker M, Kirkwood JR Recognition of vertebral fracture in a clinical setting. Osteoporos Int. 2000;11(7):577-582.

8. Diamond TH, Champion B, Clark WA. Management of acute osteoporotic vertebral fractures: a nonrandomized trial comparing percutaneous vertebroplasty with conservative therapy. Am J Med. 2003;114(4):257-265.

9. Silverman SL. The clinical consequences of vertebral compression frac ture. Bone. 1992;13(suppl 2):S27-S31.

10. Hall SE, Criddle RA, Comito TL, Prince RL. A case-control study of quality of life and functional impairment in women with long-standing vertebral osteoporotic fracture. Osteoporos Int. 1999;9(6):508-515.

11. Salaffi F, Cimmino MA, Malavolta N, et al. The burden of prevalent fractures on health-related quality of life in postmenopausal women with osteoporosis: the IMOF study. J Rheumatol. 2007;34(7):1551-1560.

12. Silverman SL, Minshall ME, Shen W, Harper KD, Xie S. The relationship of health-related quality of life to prevalent and incident vertebral fractures in postmenopausal women with osteoporosis: results from the Multiple Outcomes of Raloxifene Evaluation Study. Arthritis Rheum 2001; 44(11):2611-2619

13. Nevitt MC, Ettinger B, Black DM, et al. The association of radiographically detected vertebral fractures with back pain and function: a prospective study. Ann Int Med. 1998;128:793-800.

14. Center JR, Nguyen TV, Schneider D, Sambrook PN, Eisman JA. Mortality after all major types of osteoporotic fracture in men and women: an observational study. Lancet. 13 1999;353(9156):878-882.

15. Cooper C, Atkinson EJ, Jacobsen SJ, O’Fallon WM, Melton LJ 3rd. Population-based study of survival after osteoporotic fractures. Am J Epidemiol. 1993;137(9):1001-1005.

16. Kanis JA, Oden A, Johnell O, De Laet C, Jonsson B. Excess mortality after hospitalisation for vertebral fracture. Osteoporos Int. 2004;15(2):108-112.

17. Dolan P, Torgerson DJ. The cost of treating osteoporotic fractures in the United Kingdom female population. Osteoporos Int. 1998;8(6):611-617.

18. Gabriel SE, Tosteson AN, Leibson CL, et al. Direct medical costs attributable to osteoporotic fractures. Osteoporos Int. 2002;13(4):323-330.

19. Ray NF, Chan JK, Thamer M, Melton LJ 3rd. Medical expenditures for the treatment of osteoporotic fractures in the United States in 1995: report from the National Osteoporosis Foundation. J Bone Miner Res. 1997; 12(1):24-35.

20. Crandall C. Laboratory workup for osteoporosis. Which tests are most cost-effective? Postgrad Med. 2003;114(3):35-38, 41-34.
21. National Osteoporosis Foundation. Clinician's Guide to Prevention and Treatment of Osteoporosis. Available at: http://www.nof.org/professionals/Clinicians_Guide.htm. Accessed February 2009.

22. Holick M, Siris E, Binkley N, et al. Prevalence of vitamin D inadequacy among postmenopausal North American women receiving osteoporosis therapy. J Clin Endocr Metab. 2005;90:3215-3224.

23. Simonelli CS, Weiss TW, Morancey J, Swanson L, Chen Y. Prevalence of vitamin D inadequacy in a minimal trauma fracture population. Curr Med Res Opin. 2005;21:1069-1074.

24. LeBoff MS, Kohlmeier L, Hurwitz S, Franklin J, Wright J, Glowacki J. Occult vitamin D deficiency in postmenopausal US women with acute hip fracture. JAMA. 1999;281:1505-1511.

25. Edwards BJ, Langman CB, Bunta AD, Vicuna M, Favus M. Secondary contributors for bone loss in osteoporotic hip fractures. Osteoporos Int. 2008;19(7):991-999

26. Kleerekoper M. Evaluation of the patient with osteoporosis or at risk for osteoporosis. In: Marcus R, Feldman D, Kelsey J, eds. Osteoporosis. Vol. 2. San Diego: Academic Press; 2001:403-408.

27. Knopp JA, Diner BM, Blitz M, Lyritis GP, Rowe BH. Calcitonin for treating acute pain of osteoporotic vertebral compression fractures: a systematic review of randomized, controlled trials. Osteoporos Int. 2005;16(10): 1281-1290.

28. Azria M. Possible mechanisms of the analgesic action of calcitonin. Bone. 2002;30(5 suppl):80S-83S.

29. Armingeat $\mathrm{T}$, Brondino $\mathrm{R}$, Pham $\mathrm{T}$, Legre V, Lafforgue P. Intravenous pamidronate for pain relief in recent osteoporotic vertebral compression fracture: a randomized double-blind controlled study. Osteoporos Int. 2006;17(11):1659-1665.

30. Allman RM, Goode PS, Patrick MM, Burst N, Bartolucci AA. Pressure ulcer risk factors among hospitalized patients with activity limitation. JAMA. 1995;273(11):865-870.

31. Anderson FA Jr, Spencer FA. Risk factors for venous thromboembolism Circulation. 17 2003;107(23 suppl 1):I9-I16.

32. Beck-Sague C, Banerjee S, Jarvis WR. Infectious diseases and mortality among US nursing home residents. Am J Public Health. 1993;83(12): 1739-1742.

33. Loeb M, McGeer A, McArthur M, Walter S, Simor AE. Risk factors for pneumonia and other lower respiratory tract infections in elderly residents of long-term care facilities. Arch Intern Med. 27 1999;159(17): 2058-2064.

34. Malmros B, Mortensen L, Jensen MB, Charles P. Positive effects of physiotherapy on chronic pain and performance in osteoporosis. Osteoporos Int. 1998;8(3):215-221.

35. Bonner FJ Jr, Sinaki M, Grabois M, et al. Health professional's guide to rehabilitation of the patient with osteoporosis. Osteoporos Int. 2003; 14(suppl 2):S1-S22.

36. Mazanec DJ, Podichetty VK, Mompoint A, Potnis A. Vertebral compression fractures: manage aggressively to prevent sequelae. Cleve Clin J Med. 2003;70(2):147-156. Reprinted with permission. Copyright (c) 2003 Cleveland Clinic Foundation. All rights reserved.

37. Morrison WB, Parker L, Frangos AJ, Carrino JA. Vertebroplasty in the United States: guidance method and provider distribution, 2001-2003. Radiology. 2007;243(1):166-170.

38. Gray DT, Hollingworth W, Onwudiwe N, Deyo RA, Jarvik JG. Thoracic and lumbar vertebroplasties performed in US Medicare enrollees, 20012005. JAMA. 2007;298(15):1760-1762.

39. Taylor RS, Taylor RJ, Fritzell P. Balloon kyphoplasty and vertebroplasty for vertebral compression fractures: a comparative systematic review of efficacy and safety. Spine. 2006;31(23):2747-2755.

40. Bouza C, Lopez T, Magro A, Navalpotro L, Amate JM. Efficacy and safety of balloon kyphoplasty in the treatment of vertebral compression fractures: a systematic review. Eur Spine J. 2006;15(7):1050-1067.

41. Hulme PA, Krebs J, Ferguson SJ, Berlemann U. Vertebroplasty and kyphoplasty: a systematic review of 69 clinical studies. Spine. 2006;31(17):1983-2001.

42. Voormolen MH, Mali WP, Lohle PN, et al. Percutaneous vertebroplasty compared with optimal pain medication treatment: short-term clinical outcome of patients with subacute or chronic painful osteoporotic 
vertebral compression fractures. The VERTOS study. AJNR Am J Neuroradiol. 2007;28(3):555-560.

43. Lavelle WF, Cheney R. Recurrent fracture after vertebral kyphoplasty. Spine J. 2006;6(5):488-493.

44. Trout AT, Kallmes DF. Does vertebroplasty cause incident vertebral fractures? A review of available data. AJNR Am J Neuroradiol. 2006;27(7): 1397-1403.

45. Centers for Medicare and Medicaid Services. Agency for Healthcare Research and Quality (AHRQ). Technology Assessment. Percutaneous Kyphoplasty for Vertebral Fractures Caused by Osteoporosis and Malignancy, 2005. Available at: http://www.cms.hhs.gov/mcd/viewtechassess.asp?from2=viewtechassess. asp\&where $=$ index\&tid $=25 \&$. Accessed February 2009.

46. Hollingworth W, Jarvik JG. Evidence on the effectiveness and cost-effectiveness of vertebroplasty: a review of policy makers' responses. Acad Radiol. 2006;13(5):550-555.

47. Kallmes DF. Randomized vertebroplasty trials: current status and challenges. Acad Radiol. 2006;13(5):546-549.

48. Klazen CA, Verhaar HJ, Lampmann LE, et al. VERTOS II: percutaneous vertebroplasty versus conservative therapy in patients with painful osteoporotic vertebral compression fractures; rationale, objectives and design of a multicenter randomized controlled trial. Trials. 2007;8(1):33.

49. Buchbinder R, Osborne RH. Vertebroplasty: a promising but as yet unproven intervention for painful osteoporotic spinal fractures. Med J Aust. 2006;185(7):351-352.

50. Andrade SE, Majumdar SR, Chan KA, et al. Low frequency of treatment of osteoporosis among postmenopausal women following a fracture. Arch Intern Med. 2003;163(17):2052-2057.

51. Kamel HK, Hussain MS, Tariq S, Perry HM, Morley JE. Failure to diagnose and treat osteoporosis in elderly patients hospitalized with hip fracture. Am J Med. 2000;109(4):326-328.

52. Smith MD, Ross W, Ahern MJ. Missing a therapeutic window of opportunity: an audit of patients attending a tertiary teaching hospital with potentially osteoporotic hip and wrist fractures. J Rheumatol. 2001;28(11):2504-2508.

53. Solomon DH, Finkelstein JS, Katz JN, Mogun H, Avorn J. Underuse of osteoporosis medications in elderly patients with fractures. Am J Med. 2003;115(5):398-400.
54. Black DM, Cummings SR, Karpf DB, et al. Randomised trial of effect of alendronate on risk of fracture in women with existing vertebral fractures. Fracture Intervention Trial Research Group. Lancet. 1996;348(9041): 1535-1541.

55. Cranney A, Guyatt G, Griffith L, Wells G, Tugwell P, Rosen C. Meta-analyses of therapies for postmenopausal osteoporosis. IX: Summary of metaanalyses of therapies for postmenopausal osteoporosis. Endocr Rev. 2002; 23(4):570-578.

56. Guyatt GH, Cranney A, Griffith L, et al. Summary of meta-analyses of therapies for postmenopausal osteoporosis and the relationship between bone density and fractures. Endocrinol Metab Clin North Am. 2002;31(3): 659-679, xii.

57. Harris ST, Watts NB, Genant HK, et al. Effects of risedronate treatment on vertebral and nonvertebral fractures in women with postmenopausal osteoporosis: a randomized controlled trial. Vertebral Efficacy With Risedronate Therapy (VERT) Study Group. JAMA. 1999;282(14):13441352.

58. McClung MR, Geusens P, Miller PD, et al. Effect of risedronate on the risk of hip fracture in elderly women. Hip Intervention Program Study Group. N Engl J Med. 2001;344(5):333-340.

59. Chesnut IC, Skag A, Christiansen C, et al. Effects of oral ibandronate administered daily or intermittently on fracture risk in postmenopausal osteoporosis. J Bone Miner Res. 2004;19(8):1241-1249.

60. Black DM, Delmas PD, Eastell R, et al. Once-yearly zoledronic acid for treatment of postmenopausal osteoporosis. N Engl J Med. 3 2007;356(18): 1809-1822.

61. Rosen CJ. Clinical practice. Postmenopausal osteoporosis. N Engl J Med. 2005;353(6):595-603.

62. American College of Rheumatology Ad Hoc Committee on Glucocorticoid-Induced Osteoporosis.Recommendations for the prevention and treatment of glucocorticoid-induced osteoporosis: 2001 update. [Review]. Arthritis Rheum. 2001; 44(7):1496-1503.

63. Edwards BJ, Bunta AD, Madison LD, et al. An osteoporosis and fracture intervention program increases the diagnosis and treatment for osteoporosis for patients with minimal trauma fractures. Jt Comm J Qual Patient Saf. 2005; 31(5):267-274. 